\title{
Efficacy and Degree of Bias in Knee Injury Prevention Studies: A Systematic Review of RCTs
}

\author{
Nathan L. Grimm BS, Kevin G. Shea MD, \\ Ryan W. Leaver DPT, Stephen K. Aoki MD, \\ James L. Carey MD, MPH
}

Received: 9 February 2012/Accepted: 14 August 2012/Published online: 8 September 2012

(C) The Association of Bone and Joint Surgeons (B) 2012

\begin{abstract}
Background Knee injury prevention programs have been developed to address the epidemic of knee injuries in young athletes. These programs include exercises that focus on balance, proprioception, and neuromuscular control. Some studies have suggested such specialized exercise programs may reduce the risk of knee injury.

Questions/purposes We conducted a systematic review of randomized controlled trials (RCTs) of knee injury prevention programs and evaluated the risks of bias in these studies.
\end{abstract}

Each author certifies that he or she, or a member of his or her immediate family, has no commercial associations (eg, consultancies, stock ownership, equity interest, patent/licensing arrangements, etc) that might pose a conflict of interest in connection with the submitted article.

All ICMJE Conflict of Interest Forms for authors and Clinical Orthopaedics and Related Research editors and board members are on file with the publication and can be viewed on request.

This work was primarily performed at the University of Utah School of Medicine, Salt Lake City, UT, USA.

N. L. Grimm ( $₫)$, S. K. Aoki

Department of Orthopaedics, University of Utah

School of Medicine, 516 Medical Plaza,

Salt Lake City, UT 84112, USA

e-mail: nathan.grimm@hsc.utah.edu

K. G. Shea

St Luke's Intermountain Orthopaedics, Boise, ID, USA

R. W. Leaver

Department of Physiotherapy, Allan McGavin Sports

Medicine Centre, Vancouver, BC, Canada

J. L. Carey

Department of Orthopaedics, University of Pennsylvania

Health System, Philadelphia, PA, USA
Methods We performed a systematic search using MEDLINE (from 1966), CINAHL (from 1982), Cochrane (CENTRAL), and EMBASE (from 1974) in April 2011. The searches were limited to RCTs. Two reviewers independently assessed the internal validity of the included studies using the van Tulder critical appraisal tool for RCTs. Authors were contacted when internal validity was unclear in the methodology. Ten Level I studies (RCTs) met the inclusion criteria. The average risk of bias score for these studies was 7 of 11 (range, 5-10).

Results Two of the 10 studies reported a reduction in knee injuries. Of the three studies that provided ACL injuries as an outcome measure, none showed a reduction in overall ACL injury.

Conclusions Current evidence suggests most (eight of 10) well-designed RCTs show no difference of treatment benefit. Perhaps refinements of interventions may lead to a reduction in knee and ACL injuries in future trials. Limitations in the number and heterogeneity of currently published RCTs of injury prevention programs place restraints on quantifying intervention efficacy with a meta-analytic approach. Future research articles should more clearly describe the different elements of their methodology, consistent with the standards set forth by the CONSORT statement.

\section{Introduction}

$\mathrm{ACL}$ and acute knee injuries are increasingly recognized as serious problems in young athletes. In particular, female athletes have a three to five times higher risk of serious knee injury, compared with male athletes competing in similar sports $[1-3,9,35]$. The sports medicine community has focused on research and training programs to reduce these injuries. 
Four categories of risk factors for noncontact ACL injuries were identified by a group of experts in several fields: physicians, physical therapists, epidemiologists, athletic trainers, and biomechanists [17]. This group divided risk factors into several categories: environmental, anatomic, hormonal, and neuromuscular, each with its own subcategories. To date, most preventative research has been aimed at targeting strength issues and neuromuscular development and control.

During the last 30 years, numerous centers [7, 8, 14, 18, $20,25,27,33]$ have developed intervention programs designed to reduce the risk of ACL and other serious knee injuries in young athletes. Many programs document trends toward reducing knee injuries in treatment groups compared with control groups [18, 20, 23, 27, 32]; however, only two $[8,25]$ reported a statistically significant trend.

The purposes of our review therefore are to: (1) coalesce the primary literature of randomized controlled trials (RCTs) on knee injury prevention programs and critically evaluate the methodologic elements of the individual studies for internal validity; (2) analyze the overall injury prevention effectiveness of the identified literature, and (3) determine the degree of publication bias of RCTs of knee injury prevention studies.

\section{Search Strategy and Criteria}

We searched medical literature databases using the search terms "knee," “injur\$”, "ACL", "prevent\$”, and "anterior cruciate ligament" in an attempt to identify the primary literature on injury prevention programs for knee and ACL injuries. The search range was from inception to April 2011 for the following databases: MEDLINE via PubMed, EMBASE, CENTRAL-Cochrane Database, and CINAHL using the following search criteria: (("knee injuries"[MeSH Terms] OR ("knee"[All Fields] AND "injuries"[All Fields]) OR "knee injuries"[All Fields] OR ("knee"[All Fields] AND “injury"[All Fields]) OR "knee injury"[All Fields]) AND ("prevention and control"[Subheading] OR ("prevention"[All Fields] AND "control"[All Fields]) OR "prevention and control"[All Fields] OR "prevention"[All Fields])) AND Clinical Trial[ptyp] and (ACL[All Fields] AND ("Inj Prev"[Journal] OR ("injury"[All Fields] AND "prevention"[All Fields]) OR “injury prevention"[All Fields])) AND Clinical Trial[ptyp]. The search included supplemental bibliographic reference searches of articles to identify potentially missed, relevant studies. The search strategy applied to the literature databases (PubMed, CINAHL, EMBASE) yielded a total of 374 articles.

Studies eligible for inclusion had to be RCTs, as defined by the Cochrane Handbook [21]; include ACL and/or knee injuries as an outcome measure; and involve interventions focusing on injury prevention. We excluded studies if they did not include either ACL or knee injuries as an outcome measure. Additionally, studies were excluded if they were nonrandomized, used only an exogenous modality (eg, bracing), and did not involve a jumping and/or cutting sport/activity. The rationale for the latter was, typically, noncutting sports have a low incidence of ligamentous injury about the knee $[36,43]$, and injury prevention would be too heterogeneous to compare. Our study design was not exclusive to one sex, age group, sport, or playing level. Our definition of knee injury for study inclusion was any trauma, whether contact or noncontact, whether acute or overuse, whether ligamentous or nonligamentous, occurring to the knee. Acute injuries were those with sudden onset with obvious trauma and overuse injuries were those occurring with an insidious onset.

Two reviewers (NLG, RWL) independently conducted the article selection and review process. The identified articles were reviewed to determine whether they met the inclusion and exclusion criteria. When disagreements were noted, a third reviewer (KGS) facilitated group consensus agreement. After application of inclusion and exclusion criteria to titles, abstracts, and full text, 11 of the 374 articles [6, 11-13, 16, 18, 28, 45-47, 50] were eligible for more detailed review (Fig. 1). Of the 11 articles initially included, one study [18] was excluded because the randomization scheme was inappropriate, according to direct contact with the authors. Therefore, 10 studies [6, 11-13, $16,28,45-47,50]$ met the inclusion criteria for systematic review (Table 1). Of the studies included, seven were designed for soccer player injury prevention [11-13, 16, 45-47], two for handball injury prevention [28, 50], and one for active army recruits [6]. All but one study [13] used a prospective, cluster-randomized controlled study design scheme (Table 1).

The primary outcomes of interest for this study were specific to reporting of knee injuries and/or ACL injuries. Although several studies reported secondary outcomes (ankle, hamstring, upper extremity, etc), our review focused on the studies including data relative to the knee and, more specifically, ACL injuries. However, when methodologic (Table 2) or outcome data (Table 3) were not explicitly identifiable in the analysis, we contacted the authors to clarify or verify the unclear or missing data. Included studies were evaluated for degree of clinical, methodologic, and statistical heterogeneity to determine the appropriateness of pooling data for meta-analysis.

A qualitative assessment of the heterogeneity of the included studies showed substantial differences among the interventions used in the studies. For example, a subset of the studies used an intervention program focusing on balance and proprioception $[13,45,50]$. Another subset used a 
Fig. 1 A PRISMA flow diagram shows the selection process for studies included in our review.

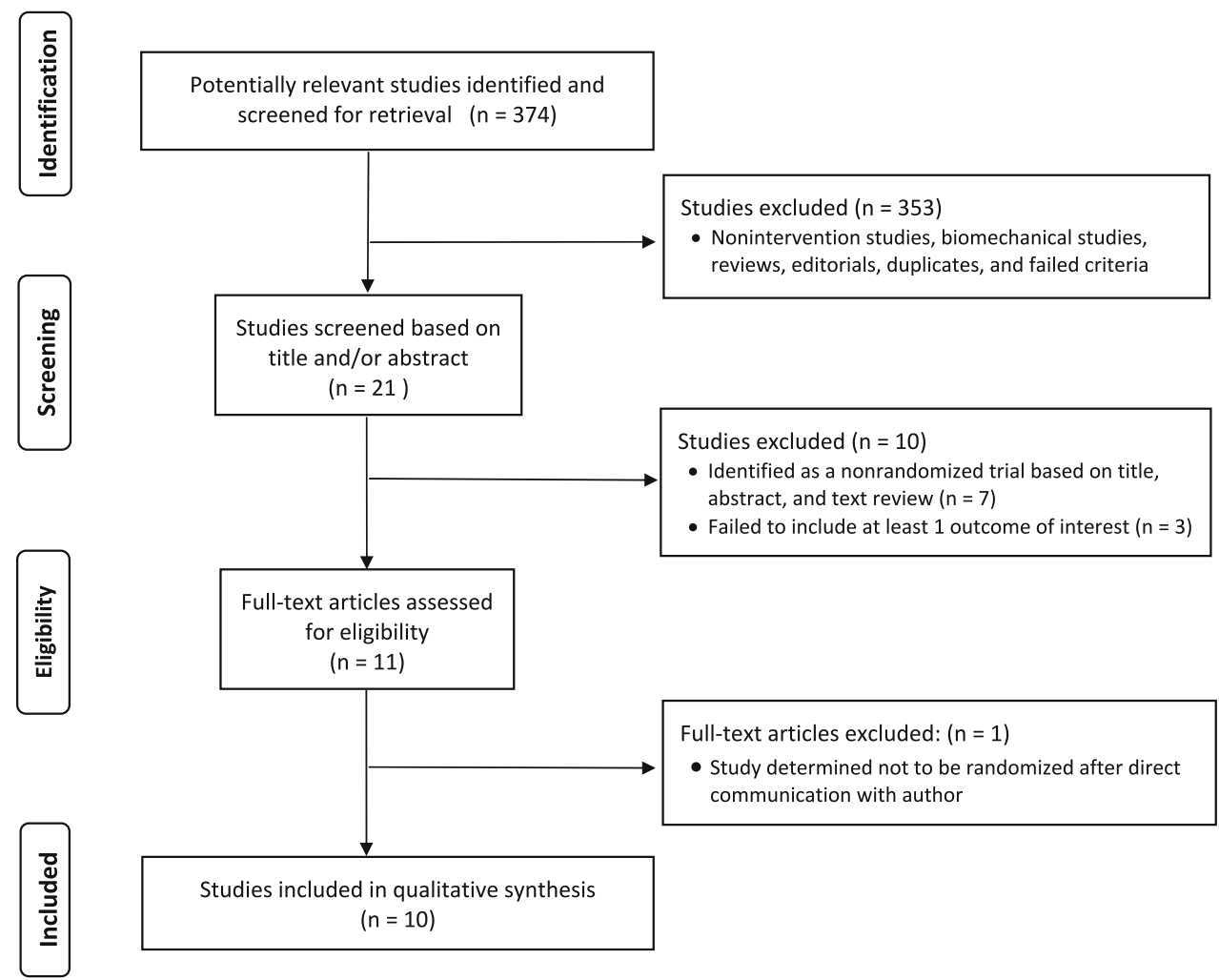

multifaceted intervention approach consisting of strengthening, balance, stretching, or warmup $[11,12,16,28,46$, 47] (Table 1), whereas the remaining study focused solely on strengthening as its intervention [6].

Regarding the three studies that included ACL injury as an outcome measure, statistical testing showed a degree of statistical heterogeneity, which would not be appropriate for combining the separate trial estimates. Moreover, several studies had missing or incomplete data pertaining to the outcomes we were interested in evaluating. Therefore, quantitative pooling of data to perform a meta-analysis was deemed inappropriate.

We also reviewed the studies for several design elements using the scale of van Tulder et al. [48], including (1) randomization method, (2) concealment of allocation, (3) group similarities, (4) blinding of subject, provider, and outcome assessor, (5) cointerventions avoided or similar, (6) intention-to-treat analysis (ITT), (7) high dropout rates, (8) compliance, and (9) timing of outcome assessment. The literature suggests that Elements 1, 2, 4, 6, and 7 can lead to an exaggeration of treatment effects [34, 37, 39-42, 51].

Two reviewers (NLG, RWL) independently appraised the content of the included articles using a pretested and standardized data abstraction instrument [48]. Again, discrepancies and disagreements were resolved by bringing in a third reviewer (KGS). When the internal validity elements were either missing or not clear, we contacted the authors of the studies for verification or clarification. The analysis of publication bias and funnel plot derivation was performed with STATA ${ }^{\circledR}$ statistical software (Release 11; StataCorp LP, College Station, TX, USA) using Egger's test and Begg's test, which are general approaches to test publication bias in the meta-analysis. Egger's test has been widely used and has become a standard procedure [21, 31]. This test is based on a linear regression approach, which is parametric. However, Begg's test is based on a rank correlation method, which is nonparametric. However, both tests have the power to detect publication bias even with a small study sample.

\section{Results}

Using a priori inclusion and exclusion criteria our search yielded 10 RCTs of knee injury prevention programs from major medical literature databases. The methodologic design elements for each of these studies were reviewed using the van Tulder scale [48], and the average risk of bias score for these studies was 7 of 11 (range, 5-10) (Table 2). Blinding of subjects and/or care providers was absent in the majority of the studies; however, given the nature of the study designs, this was difficult or impossible to accomplish. All randomized studies had adequate randomization methods. Appropriate concealment of allocations was found in all studies but one [16]. Of the studies reviewed, seven of 10 used an ITT analysis as part of their statistical 


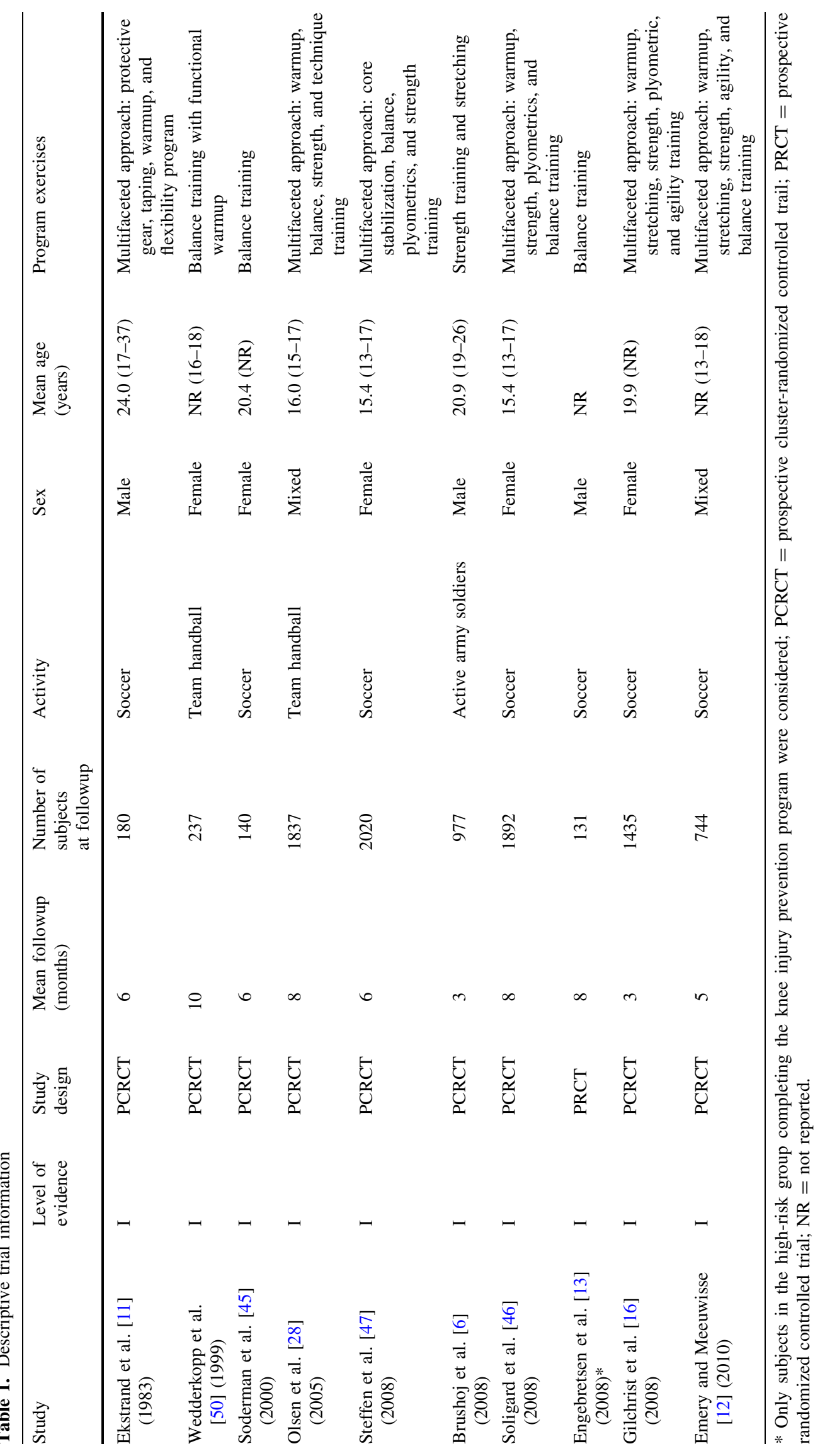


Table 2. Methodologic risk of bias results according to the van Tulder scale [48]

\begin{tabular}{|c|c|c|c|c|c|c|c|c|c|c|}
\hline $\begin{array}{l}\text { Methodologic } \\
\text { design element }\end{array}$ & $\begin{array}{l}\text { Ekstrand } \\
\text { et al. [11] }\end{array}$ & $\begin{array}{l}\text { Wedderkopp } \\
\text { et al. [50]** }\end{array}$ & $\begin{array}{l}\text { Soderman } \\
\text { et al. [45] }\end{array}$ & $\begin{array}{l}\text { Olsen } \\
\text { et al. } \\
\text { [28] }\end{array}$ & $\begin{array}{l}\text { Steffen } \\
\text { et al. } \\
\text { [47] }\end{array}$ & $\begin{array}{l}\text { Brushoj } \\
\text { et al. } \\
{[6]^{* *}}\end{array}$ & $\begin{array}{l}\text { Soligard } \\
\text { et al. } \\
\text { [46] }\end{array}$ & $\begin{array}{l}\text { Engebretsen } \\
\text { et al. [13] }\end{array}$ & $\begin{array}{l}\text { Gilchrist } \\
\text { et al. [16] }\end{array}$ & $\begin{array}{l}\text { Emery and } \\
\text { Meeuwisse } \\
{[12]}\end{array}$ \\
\hline $\begin{array}{l}\text { Adequate } \\
\text { randomization }\end{array}$ & Yes* & Yes* & Yes* & Yes* & Yes & Yes & Yes* & Yes* & Yes* & Yes* \\
\hline $\begin{array}{l}\text { Concealment of } \\
\text { allocations }\end{array}$ & Yes* & Yes* & Yes* & Yes & Yes* & Yes & Yes & Yes* & No & Yes* \\
\hline $\begin{array}{l}\text { Homogeneity of } \\
\text { cohort }\end{array}$ & Yes & Yes & Yes & Yes & Yes & Yes & Yes & No & Yes & Yes \\
\hline Subject blinding & No & No & No & No & No & Yes & No & No & No & No \\
\hline $\begin{array}{l}\text { Care provider } \\
\text { blinding }\end{array}$ & No & No & No & No & No & Yes* & No & No & No & No \\
\hline $\begin{array}{l}\text { Outcome assessor } \\
\text { blinding }\end{array}$ & No & Yes & No & Yes & Yes & Yes & Yes & No & No & Yes \\
\hline $\begin{array}{l}\text { Cointerventions } \\
\text { avoided or } \\
\text { similar }\end{array}$ & No & Yes* & Yes & Yes & Yes & Yes & Yes & Yes & Yes & Yes \\
\hline $\begin{array}{l}\text { Adequate } \\
\text { compliance }\end{array}$ & Yes* & Yes* & Yes & No & No & Yes & Yes & No & No* & No \\
\hline $\begin{array}{l}\text { Acceptable dropout } \\
\text { rate with } \\
\text { description }\end{array}$ & No* & No* & No & No & Yes & Yes & Yes & No & Yes & Yes \\
\hline $\begin{array}{l}\text { Timing of outcome } \\
\text { assessment }\end{array}$ & Yes & Yes & Yes & Yes & Yes & Yes & Yes & Yes & Yes & Yes \\
\hline $\begin{array}{l}\text { Intention-to-treat } \\
\text { analysis }\end{array}$ & Yes* & Yes* & No & Yes & Yes & $\mathrm{No}^{*}$ & Yes & Yes & No & Yes \\
\hline Total score & 6 & 8 & 6 & 7 & 8 & 10 & 9 & 5 & 5 & 8 \\
\hline
\end{tabular}

* Not found in text of manuscript but verified through direct communication with the author; $* *$ studies requiring consensus protocol for inclusion.

Table 3. Quantitative outcome data

\begin{tabular}{|c|c|c|c|c|c|c|c|}
\hline \multirow[t]{2}{*}{ Study } & \multicolumn{3}{|l|}{ Knee injuries } & \multicolumn{3}{|l|}{ ACL injuries } & \multirow[t]{2}{*}{ Power analysis } \\
\hline & Prevention & Control & p value* & Prevention & Control & p value* & \\
\hline Ekstrand et al. [11] & $1.1 \%(1$ of 90$)$ & $18.9 \%(17$ of 90$)$ & $<0.05$ & NR & NR & NR & NR \\
\hline Wedderkopp et al. [50] & $1.8 \%(2$ of 111) & $6.3 \%(8$ of 126$)$ & $>0.05$ & NR & NR & NR & NR \\
\hline Soderman et al. [45] & $12.9 \%$ & $7.7 \%^{\ddagger}(6$ of 78$)$ & NR & $6.5 \%$ & $1.3 \%^{\ddagger}(1$ of 78$)$ & NR & Yes (a priori) \\
\hline Olsen et al. [28] & $2.0 \%(19$ of 958$)$ & $4.3 \%$ (38 of 879$)$ & $\leq 0.05$ & $0.3 \%$ (3 of 958) & $1.1 \%(10$ of 879$)$ & $>0.05^{\ddagger}$ & Yes (a priori) \\
\hline Steffen et al. [47] & $3.4 \%(37$ of 1073$)$ & $3.2 \%$ (30 of 947$)$ & $>0.05$ & NR & NR & NR & Yes (a priori) \\
\hline Brushoj et al. [6] & $13.6 \%(66$ of 487$)$ & $11.6 \%(57$ of 490$)$ & $>0.05$ & NR & NR & NR & Yes (a priori) \\
\hline Soligard et al. [46] & $3.1 \%(33$ of 1055$)$ & $5.6 \%$ (47 of 837$)$ & 0.08 & NR & NR & NR & Yes (a priori) \\
\hline Engebretson et al. $[13]^{\dagger}$ & $10.8 \%(7$ of 65$)$ & $12.1 \%(8$ of 66$)$ & 0.93 & NR & NR & NR & NR \\
\hline Gilchrist et al. [16] & $6.9 \%(40$ of 583$)$ & $6.8 \%(58$ of 852$)$ & 0.86 & $1.2 \%(7$ of 583$)$ & $2.1 \%(18$ of 852$)$ & 0.20 & Yes (a priori) \\
\hline Emery and Meeuwisse [12] & $0.8 \%$ (3 of 380) & $2.2 \%(8$ of 364$)$ & 0.23 & NR & NR & NR & Yes (a priori) \\
\hline
\end{tabular}

* As reported in individual studies using complex statistical calculations appropriate for cluster randomization; ${ }^{\dagger}$ only subjects from the high-risk group were analyzed, as knee injuries were compared for only this group; ${ }^{*}$ data verified by direct communication with author; NR = not reported.

methods. Although all internal validity measures were obtained from each study, we contacted the authors of all studies to clarify at least one element described by the van Tulder scale (Table 2).

Of the studies reviewed that reported knee injury as an outcome measure, two of $10[11,28]$ showed a reduction in knee injuries whereas seven of $10[6,12,13,16,46,47,50]$ showed no reduction in overall knee injuries and one of 10 [45] did not provide the $\mathrm{p}$ value for the knee injury comparison we analyzed (Table 3). In comparison, of the studies that reported ACL injuries as an outcome measure, none of the three $[16,28,45]$ showed a reduction in overall 


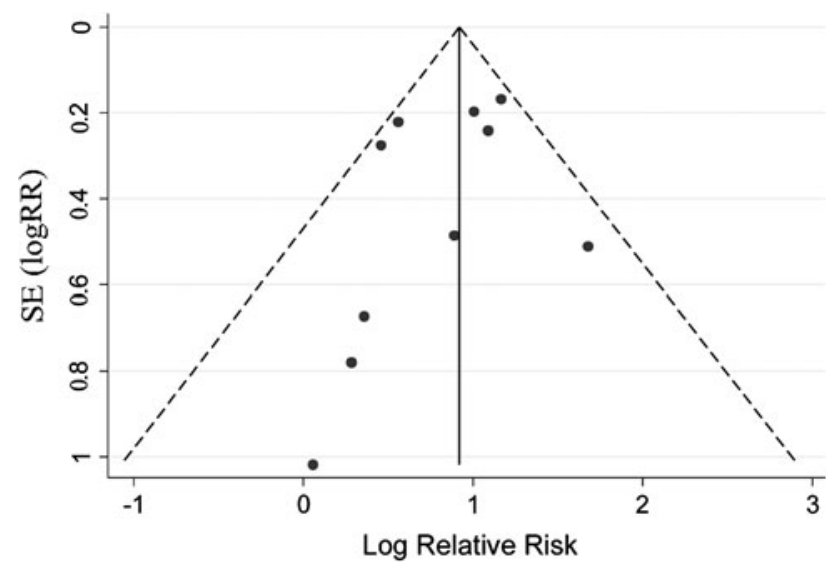

Fig. 2 A funnel plot with 95\% confidence limits shows no gross publication bias. SE $(\operatorname{logRR})=$ standard error of the natural logarithm of the relative risk.

ACL injuries (Table 3). Four of the studies reported a nonsignificant increase in the proportion of knee injuries in the intervention group [6, 16, 45, 47], one of which reported a higher proportion of ACL injuries in the intervention group [45].

Regarding publication bias, after comparing the calculated relative risks of the studies published thus far on knee and/or ACL injury prevention programs, it appeared there was no gross publication bias as can be seen by the inverted shape of the funnel plot [10] (Fig. 2). This was confirmed by Egger's test $(\mathrm{p}=0.106)$ and Begg's test $(\mathrm{p}=0.107)$.

\section{Discussion}

Knee injuries create one of the highest clinical and public health, injury-related burdens given their ubiquity across the age continuum and their need for surgical intervention [15]. Furthermore, the knee is the most commonly injured joint in adolescent athletes [44] and more specifically the $\mathrm{ACL}$ is one of the most commonly injured knee structures in this age group [43]. The public, athletes, coaches, and researchers are becoming increasingly aware of this fact and injury prevention programs have been developed in an attempt to address this issue. However, only a handful of Level I studies have been designed to evaluate if specialized injury prevention programs can reduce knee injuries. The current study was a systematic review, which evaluated the internal validity, or risk of bias, of RCTs of knee injury prevention studies. This study also compared effectiveness reported in each trial and quantified the degree of publication bias on reporting of knee injury prevention.

Although we adhered to a strict protocol for collection, interpretation, and analysis, our study is not without limitations. First, we did not blind the reviewers to study author, institution, or journal in which the study was published. Although the extra step of blinding the reviewed manuscripts has been done in other reviews, it is an onerous extra step with little evidence to support its ability to protect against bias in systematic reviews and no difference in evaluation results have been shown [5]. Second, our definition of knee injury was broad and did not narrow down injuries to a single structure (eg, ACL). Our a priori definition was designed to capture relevant trials of knee injuries. In retrospect, had we operationalized knee injury to include only ligamentous injuries it would have yielded too few studies (three), which would have yielded a review of questionable value. Third, one of the authors (KGS) has published on knee injury prevention programs [33], which showed no treatment benefit, and an argument could be made that this could introduce selection bias. However, we attempted to control for this by removing this author as a reviewer of selected studies and involving him only when there were discrepancies needing consensus resolution. For example, if randomization was unclear to one reviewer but clear and appropriate to another, our third reviewer (KGS) was asked to review and discuss the study for a consensus agreement. Additionally, use of consensus agreement only occurred with two studies. First was inclusion of the study by Soderman et al. [45] owing to a missing $p$ value; on consensus the three reviewers agreed that this study still yielded valuable information regarding study design, quality, and it was understood at that point pooling of data would not be possible owing to the degree of heterogeneity. Second was the inclusion of the study by Brushoj et al. [6].

Although the study by Brushoj et al. [6] looked exclusively at overuse injuries, this study fit our inclusion criteria for including knee injuries. Additionally, as Bahr [4] stated, overuse injuries can overlap with acute injuries and in some cases present as an acute injury. Furthermore, previous studies have suggested that injury prevention for acute injuries may be a way to prevent overuse injuries [24, $29,30]$. We found it appropriate to include this welldesigned RCT on injury prevention in our review.

It is well understood that nonrandomization has the potential to lead to systematic bias, which can overestimate or underestimate the effects of a treatment. Other design flaws can lead to bias and potential exaggeration of treatment and intervention effects. For example, the importance of ITT analysis is its ability to preserve the randomization scheme used to allocate the subjects to either a treatment or control arm reducing the degree of statistical bias. Herman et al. [19] showed there is poor use of ITT analysis in orthopaedic studies. In the series we reviewed, seven of 10 used an ITT analysis; however, only five of 10 clearly stated its use in the methods section. Additionally, studies have shown that a lack of or inadequate concealment of 
allocation leads to exaggerated effects of interventions between $30 \%$ and $40 \%$ [26, 40]. In our study, we found nine of 10 studies performed adequate concealment of allocations; however, this was clearly described in the manuscript in only three of 10 studies $[6,28,46]$. Clearly, our review has elucidated the fact that many of these RCTs are well designed; however, collectively the methodologic elements of the studies are ill-described in the body of the manuscript. This same trend was noted by Hill et al. [22] in their 2002 study of RCTs in rheumatology. As they pointed out, and we echo these concerns, the discrepancies between published reports and the actual conduct of RCTs make it difficult to conduct a best-evidence synthesis of the literature.

In our systematic review of RCTs for knee injury and ACL injury prevention, two of 10 studies $[11,28]$ showed a reduction in overall knee injury, and none of the three studies reported a reduction in overall ACL injuries. However, although there was no reduction in overall ACL injuries, a subgroup analysis performed by Gilchrist et al. [16] showed a reduction in ACL injuries for individuals who had a prior ACL injury, ACL injuries occurring during practice, and ACL injuries occurring late in the season. Of the studies that failed to show a reduction, some had fewer knee injuries [12, 13, 46, 49] and ACL injuries [16, 28] in the treatment group and some of the studies had fewer knee injuries [6, 16, 45, 47] and ACL injuries [45] in the control group. Unfortunately, owing to the degree of heterogeneity among studies and missing or incomplete data, we were unable to resolve the overall treatment effect by pooling the data in a meta-analysis. Furthermore, in instances where the $\mathrm{p}$ values were not reported, we were unable to make these calculations because of incomplete or missing data and more complex randomization statistics.

After our analysis of research on the topic of injury prevention, we concur with the conclusions of Griffin et al. [17] that "presently there is insufficient although encouraging evidence supporting the premise that ACL prevention programs improve performance and/or alter what are thought to be key risk factors for injury". At this time, some of the clinical trials suggest a treatment benefit for injury reduction, some show a harmful effect, and some show no difference. Based on this limited and conflicting information, we believe counseling patients about participation in these programs is warranted, but patients should be informed about the limited evidence of treatment efficacy. Although RCTs of this type are difficult to conduct and are logistically complex, further well-designed research trials will be necessary to determine whether these injuries can be prevented with specialized training programs and these trials should more clearly describe the different elements of their methodology, consistent with the standards set forth by the CONSORT statement [38]. In terms of future injury prevention design, the study by Olsen et al. [28] may serve as an example for future directed research on knee injury prevention, which consisted of boys and girls performing a multifaceted 15 - to 20-minute warmup program (Table 1).

Acknowledgments We thank Mary McFarland at Eccles Health Science Library for assisting with creating a sensitive search strategy for PubMed, CINAHL, and EMBASE. Her expertise was greatly appreciated. We also thank Jaewhan Kim $\mathrm{PhD}$, statistician of the Division of Public Health, and Study Design \& Biostatistics Center, University of Utah School of Medicine for statistical consultation, advice on analyzing the data of this study, and for his hard work helping analyze the extracted study data.

\section{References}

1. Agel J, Olson DE, Dick R, Arendt EA, Marshall SW, Sikka RS. Descriptive epidemiology of collegiate women's basketball injuries: National Collegiate Athletic Association Injury Surveillance System, 1988-1989 through 2003-2004. J Athl Train. 2007;42:202-210.

2. Agel J, Palmieri-Smith RM, Dick R, Wojtys EM, Marshall SW. Descriptive epidemiology of collegiate women's volleyball injuries: National Collegiate Athletic Association Injury Surveillance System, 1988-1989 through 2003-2004. J Athl Train. 2007;42:295-302.

3. Arendt E, Dick R. Knee injury patterns among men and women in collegiate basketball and soccer: NCAA data and review of literature. Am J Sports Med. 1995;23:694-701.

4. Bahr R. No injuries, but plenty of pain? On the methodology for recording overuse symptoms in sports. Br J Sports Med. 2009; 43:966-972.

5. Berlin JA. Does blinding of readers affect the results of metaanalyses? University of Pennsylvania Meta-analysis Blinding Study Group. Lancet. 1997;350:185-186.

6. Brushoj C, Larsen K, Albrecht-Beste E, Nielsen MB, Loye F, Holmich P. Prevention of overuse injuries by a concurrent exercise program in subjects exposed to an increase in training load: a randomized controlled trial of 1020 army recruits. Am J Sports Med. 2008;36:663-670.

7. Cahill BR, Griffith EH. Effect of preseason conditioning on the incidence and severity of high school football knee injuries. Am J Sports Med. 1978;6:180-184.

8. Caraffa A, Cerulli G, Projetti M, Aisa G, Rizzo A. Prevention of anterior cruciate ligament injuries in soccer: a prospective controlled study of proprioceptive training. Knee Surg Sports Traumatol Arthrosc. 1996;4:19-21.

9. Dick R, Putukian M, Agel J, Evans TA, Marshall SW. Descriptive epidemiology of collegiate women's soccer injuries: National Collegiate Athletic Association Injury Surveillance System, 1988-1989 through 2002-2003. J Athl Train. 2007;42: 278-285.

10. Egger M, Smith GD, Altman DG, eds. Systematic Reviews in Health Care: Meta-analysis in Context. London, UK: BMJ Publishing Group; 2001.

11. Ekstrand J, Gillquist J, Liljedahl SO. Prevention of soccer injuries: supervision by doctor and physiotherapist. Am J Sports Med. 1983;11:116-120.

12. Emery CA, Meeuwisse WH. The effectiveness of a neuromuscular prevention strategy to reduce injuries in youth soccer: a 
cluster-randomised controlled trial. Br J Sports Med. 2010;44: $555-562$.

13. Engebretsen AH, Myklebust G, Holme I, Engebretsen L, Bahr R. Prevention of injuries among male soccer players: a prospective, randomized intervention study targeting players with previous injuries or reduced function. Am J Sports Med. 2008;36:10521060.

14. Ettlinger CF, Johnson RJ, Shealy JE. A method to help reduce the risk of serious knee sprains incurred in alpine skiing. Am J Sports Med. 1995;23:531-537.

15. Gage BE, McIlvain NM, Collins CL, Fields SK, Comstock RD. Epidemiology of 6.6 million knee injuries presenting to United States emergency departments from 1999 through 2008. Acad Emerg Med. 2012;19:378-385.

16. Gilchrist J, Mandelbaum BR, Melancon H, Ryan GW, Silvers HJ, Griffin LY, Watanabe DS, Dick RW, Dvorak J. A randomized controlled trial to prevent noncontact anterior cruciate ligament injury in female collegiate soccer players. Am J Sports Med. 2008;36:1476-1483.

17. Griffin LY, Albohm MJ, Arendt EA, Bahr R, Beynnon BD, Demaio M, Dick RW, Engebretsen L, Garrett WE Jr, Hannafin JA, Hewett TE, Huston LJ, Ireland ML, Johnson RJ, Lephart S, Mandelbaum BR, Mann BJ, Marks PH, Marshall SW, Myklebust G, Noyes FR, Powers C, Shields C Jr, Shultz SJ, Silvers H, Slauterbeck J, Taylor DC, Teitz CC, Wojtys EM, Yu B. Understanding and preventing noncontact anterior cruciate ligament injuries: a review of the Hunt Valley II meeting, January 2005. Am J Sports Med. 2006;34:1512-1532.

18. Heidt RS Jr, Sweeterman LM, Carlonas RL, Traub JA, Tekulve FX. Avoidance of soccer injuries with preseason conditioning. Am J Sports Med. 2000;28:659-662.

19. Herman A, Botser IB, Tenenbaum S, Chechick A. Intention-totreat analysis and accounting for missing data in orthopaedic randomized clinical trials. J Bone Joint Surg Am. 2009;91:21372143.

20. Hewett TE, Lindenfeld TN, Riccobene JV, Noyes FR. The effect of neuromuscular training on the incidence of knee injury in female athletes: a prospective study. Am J Sports Med. 1999; 27:699-706

21. Higgins JPT, Green SE. Cochrane Handbook for Systematic Reviews of Interventions Version 5.0.2 [updated September 2009]. The Cochrane Collaboration, 2009. Available at: http:// www.cochrane-handbook.org. 2009. Accessed June 1, 2011.

22. Hill CL, LaValley MP, Felson DT. Discrepancy between published report and actual conduct of randomized clinical trials. $J$ Clin Epidemiol. 2002;55:783-786.

23. Junge A, Rosch D, Peterson L, Graf-Bauman T, Dvorak J. Prevention of soccer injuries: a prospective intervention study in youth amateur players. Am J Sports Med. 2002;30:652-659.

24. LaStayo PC, Woolf JM, Lewek MD, Snyder-Mackler L, Reich T, Lindstedt SL. Eccentric muscle contractions: their contribution to injury, prevention, rehabilitation, and sport. J Orthop Sports Phys Ther. 2003;33:557-571.

25. Mandelbaum BR, Silvers HJ, Watanabe DS, Knarr JF, Thomas SD, Griffin LY, Kirkendall DT, Garrett W Jr. Effectiveness of a neuromuscular and proprioceptive training program in preventing anterior cruciate ligament injuries in female athletes: 2-year follow-up. Am J Sports Med. 2005;33:1003-1010.

26. Moher D, Pham B, Jones A, Cook DJ, Jadad AR, Moher M, Tugwell P, Klassen TP. Does quality of reports of randomised trials affect estimates of intervention efficacy reported in metaanalyses? Lancet. 1998;352:609-613.

27. Myklebust G, Engebretsen L, Braekken IH, Skjolberg A, Olsen OE, Bahr R. Prevention of anterior cruciate ligament injuries in female team handball players: a prospective intervention study over three seasons. Clin J Sport Med. 2003;13:71-78.
28. Olsen OE, Myklebust G, Engebretsen L, Holme I, Bahr R. Exercises to prevent lower limb injuries in youth sports: cluster randomised controlled trial. BMJ. 2005;330:449.

29. O'Toole ML. Prevention and treatment of injuries to runners. Med Sci Sports Exerc. 1992;24(9 suppl):S360-363.

30. Parkkari J, Kujala UM, Kannus P. Is it possible to prevent sports injuries? Review of controlled clinical trials and recommendations for future work. Sports Med. 2001;31:985-995.

31. Peters JL, Sutton AJ, Jones DR, Abrams KR, Rushton L. Comparison of two methods to detect publication bias in metaanalysis. JAMA. 2006;295:676-680.

32. Petersen W, Braun C, Bock W, Schmidt K, Weimann A, Drescher W, Eiling E, Stange R, Fuchs T, Hedderich J, Zantop T. A controlled prospective case control study of a prevention training program in female team handball players: the German experience. Arch Orthop Trauma Surg. 2005;125:614-621.

33. Pfeiffer RP, Shea KG, Roberts D, Grandstrand S, Bond L. Lack of effect of a knee ligament injury prevention program on the incidence of noncontact anterior cruciate ligament injury. $J$ Bone Joint Surg Am. 2006;88:1769-1774.

34. Poolman RW, Struijs PA, Krips R, Sierevelt IN, Marti RK, Farrokhyar F, Bhandari M. Reporting of outcomes in orthopaedic randomized trials: does blinding of outcome assessors matter? J Bone Joint Surg Am. 2007;89:550-558.

35. Renstrom P, Ljungqvist A, Arendt E, Beynnon B, Fukubayashi T, Garrett W, Georgoulis T, Hewett TE, Johnson R, Krosshaug T, Mandelbaum B, Micheli L, Myklebust G, Roos E, Roos H, Schamasch P, Shultz S, Werner S, Wojtys E, Engebretsen L. Non-contact ACL injuries in female athletes: an International Olympic Committee current concepts statement. Br J Sports Med. 2008; 42:394-412.

36. Ristolainen L, Heinonen A, Turunen H, Mannstrom H, Waller B, Kettunen JA, Kujala UM. Type of sport is related to injury profile: a study on cross country skiers, swimmers, long-distance runners and soccer players. A retrospective 12-month study. Scand J Med Sci Sports. 2010;20:384-393.

37. Schulz KF, Altman DG, Moher D. Allocation concealment in clinical trials. (Comment on: Correlation of quality measures with estimates of treatment effect in meta-analyses of randomized controlled trials. [JAMA. 2002]) JAMA. 2002;288:2406-2407; author reply 2408-2409.

38. Schulz KF, Altman DG, Moher D; CONSORT Group. CONSORT 2010 statement: updated guidelines for reporting parallel group randomised trials. J Clin Epidemiol. 2010;63:834-840.

39. Schulz KF, Chalmers I, Altman DG. The landscape and lexicon of blinding in randomized trials. Ann Intern Med. 2002;136:254-259.

40. Schulz KF, Chalmers I, Hayes RJ, Altman DG. Empirical evidence of bias: dimensions of methodological quality associated with estimates of treatment effects in controlled trials. JAMA. 1995;273:408-412.

41. Schulz KF, Grimes DA. Allocation concealment in randomised trials: defending against deciphering. Lancet. 2002;359:614-618.

42. Schulz KF, Grimes DA. Blinding in randomised trials: hiding who got what. Lancet. 2002;359:696-700.

43. Shea KG, Grimm NL, Ewing CK, Aoki SK. Youth sports anterior cruciate ligament and knee injury epidemiology: who is getting injured? In what sports? When? Clin Sports Med. 2011;30:691-706.

44. Simon TD, Bublitz C, Hambidge SJ. Emergency department visits among pediatric patients for sports-related injury: basic epidemiology and impact of race/ethnicity and insurance status. Pediatr Emerg Care. 2006;22:309-315.

45. Soderman K, Werner S, Pietila T, Engstrom B, Alfredson H. Balance board training: prevention of traumatic injuries of the lower extremities in female soccer players? A prospective randomized intervention study. Knee Surg Sports Traumatol Arthrosc. 2000;8:356-363. 
46. Soligard T, Myklebust G, Steffen K, Holme I, Silvers H, Bizzini M, Junge A, Dvorak J, Bahr R, Andersen TE. Comprehensive warm-up programme to prevent injuries in young female footballers: cluster randomised controlled trial. BMJ. 2008;337: a2469.

47. Steffen K, Myklebust G, Olsen OE, Holme I, Bahr R. Preventing injuries in female youth football: a cluster-randomized controlled trial. Scand J Med Sci Sports. 2008;18:605-614.

48. van Tulder M, Furlan A, Bombardier C, Bouter L; Editorial Board of the Cochrane Collaboration Back Review Group. Updated method guidelines for systematic reviews in the Cochrane Collaboration Back Review Group. Spine (Phila Pa 1976). 2003;28:1290-1299.
49. Wedderkopp N, Kaltoft M, Holm R, Froberg K. Comparison of two intervention programmes in young female players in European handball: with and without ankle disc. Scand J Med Sci Sports. 2003;13:371-375.

50. Wedderkopp N, Kaltoft M, Lundgaard B, Rosendahl M, Froberg $\mathrm{K}$. Prevention of injuries in young female players in European team handball: a prospective intervention study. Scand J Med Sci Sports. 1999;9:41-47.

51. Wood L, Egger M, Gluud LL, Schulz KF, Juni P, Altman DG, Gluud C, Martin RM, Wood AJ, Sterne JA. Empirical evidence of bias in treatment effect estimates in controlled trials with different interventions and outcomes: meta-epidemiological study. BMJ. 2008;336:601-605. 